\title{
¿ES REALMENTE ACGESORIO EL GUERPO? CUESTIONES POR RESOLVER ACERCA DEL MIND UPLOADING
}

\author{
Mikel Ostiz Blanco. Universidad de Navarra
}

Resumen: El mind uploading es el acto de transferir una mente de su sustrato original (el cuerpo biológico de la persona) a otro sustrato, que puede ser también biológico, o bien robótico o incluso digital. Esta propuesta se enmarca en el movimiento transhumanista y tiene como objetivo último la inmortalidad personal más allá de la duración temporal del cuerpo biológico. La tesis de este artículo es que el mind uploading es una propuesta que se presenta principalmente como tecnológica, pero que, en realidad, tiene implicaciones a muchos otros niveles: antropológico, cultural, político, etc., por lo que requiere una reflexión más profunda. Por ello, se analizan en este artículo dos dimensiones del mind-uploading: su posibilidad real de realización y su deseabilidad, sin pretender tanto dar respuestas finales como suscitar preguntas que se dan muchas veces por descontadas.

Palabras clave: mind-uploading, transhumanismo, filosofía de la mente, problema mente-cerebro

\section{Is the body actually dispensable? Open questions about mind uploading}

Abstract: Mind-uploading consists on transferring a mind from its original substrate (a biological body) to other substrate (other biological body, a robotic body or a digital entity). The mind uploading proposal is part of the transhumanist program and aims to reach the personal immortality after the corruption of the biological body. This paper claims that this proposal is not only a technological one (despite it is presented this way), but also an anthropological, cultural and political topic, so that a deeper reflection is desirable. In this paper two aspects of mind uploading are analyzed: the actual possibility of the mind uploading and also its desirability, with the intention of opening questions that usually are considered answered.

Keywords: mind-uploading, transhumanism, mind philosophy, mind-brain problem.

Recibido: 11 de febrero de 2019. Aprobado: 1 de junio 2020. 


\section{1. ¿Qué es el mind uploading?}

\subsection{Una cuestión más abierta de lo que parece}

La técnica del mind uploading es una técnica futurista que consiste en la transferencia de una mente a un receptáculo distinto del propio cuerpo, ya sea otro cuerpo orgánico, un cuerpo tecnológico (un cyborg) o un avatar digital. Se trata de una propuesta revolucionaria que tiene implicaciones a muchos niveles: a nivel científico, filosófico, social, político, etc., pero, ante todo, atañe a la concepción de lo que el ser humano es y lo que puede llegar a ser. Sin embargo, el mind uploading se presenta de una forma extremadamente optimista (Kurzweil, 2005), como si fuera una mera cuestión de complejidad técnica en la que, en un determinado momento, se lograría encontrar la implementación correcta para que funcione. Este artículo pretende mostrar que el estatuto del mind uploading es más complejo y que tiene cuestiones por resolver a varios niveles.

\subsection{El transhumanismo como marco interpretativo del mind uploading}

El mind uploading se enmarca en lo que se conoce como movimiento transhumanista. Este movimiento heterogéneo se caracteriza por sostener que el ser humano debe proseguir su proceso evolutivo mediante la tecnología. La nueva especie no vendría por el proceso evolutivo mediante el cual se han originado las diferentes especies que conocemos, sino que el próximo escalón evolutivo requeriría una actitud activa del ser humano. De esta forma, mediante su razón —en su dimensión científica y tecnológica eminentemente- lograría superar la naturaleza humana para llegar a un estadio post-humano o trans-humano. Que esta hipotética evolución se ciñe a las capacidades científico-técnicas del ser humano —y no a otras más, valga la redundancia, humanistas - queda patente en otros nombres que recibe el 
¿Es realmente accesorio el cuerpo?

movimiento transhumanista: Transformation Technology, Disruptive Technology o Radical Technology (Krishnan, 2012). Aún más iluminadora es la denominación de Liberation Technology (Stanford, n.d.), que precisamente recoge este sentido emancipador del mind uploading en cuanto posibilita superar las limitaciones propias del cuerpo humano, incluida su mortalidad.

Precisamente, la superación de la muerte es una de las principales metas del transhumanismo. Para ello, hay que preservar aquello que recoge la identidad personal cuando el propio cuerpo llega a su límite temporal: la mente. El mind uploading se presenta como la opción privilegiada para lograr esta meta, si bien no es la única: el head transplanting o trasplante de cabeza pretende imitar la técnica del trasplante de corazón aplicándolo al cerebro humano, buscando esa emancipación del cerebro y la mente de su contexto natural (Benedikter, Siepmann, \& Reymann, 2017, p. 39).

A nivel político y social existe un ejemplo paradigmático de cómo esta búsqueda de la inmortalidad es una meta que resulta atractiva a un sector de la población: el llamado The Immortality Bus ("The immortality bus," n.d.). El autor, publicista y candidato presidencial en 2016, Zoltan Istvan, recaudó 26100 dólares en una famosa campaña de recaudación de fondos cuya principal atracción era este autobús con forma de ataúd, que recorrió las autopistas americanas (desde San Francisco hasta Washinton DC) realizando paradas en diferentes eventos para defender que Estados Unidos debía abanderar un cambio tecnológico y cultural que dejase atrás convicciones del pasado respecto a la muerte que, según él, estaban frenando el avance médico, científico y tecnológico. Se refleja aquí que la cuestión del mind uploading no es meramente tecnológica, sino que tiene unas implicaciones antropológicas y culturales que hacen que el debate no se pueda circunscribir únicamente al ámbito de la ciencia y la tecnología.

Además, el transhumanismo no se limita a sostener que debemos superar la muerte, sino que este hito sería el culmen de una filosofía del auto-perfeccionamiento cuya herramienta es la tecnología. El post-humano - como nuevo eslabón evolutivo- debería superar las barreras biológicas y moldear 
su cuerpo y su mente con tecnología inteligente e intrusiva. El llamado enhacement incluiría la sustitución de miembros orgánicos como un ojo o un brazo por equivalentes tecnológicos mejorados: un ojo artificial que pudiera ver en la oscuridad o un brazo robótico que pudiera triplicar la fuerza de un brazo orgánico convencional. Pero donde esta mejora sería más intrusiva sería en la implantación de chips y otros sistemas similares a nivel cerebral para mejorar las capacidades cognitivas de los seres humanos. Además, en esta vertiente más neurológica, sería deseable — según este marco transhumanista- llegar al uso de fármacos que pudiesen suprimir ciertas emociones y potenciar otras: eliminar el dolor de un duelo o inducir un placer por una actividad que debe realizarse pero que en sí misma no produce placer a un individuo concreto. Resuena en este punto la magistral obra de Aldous Huxley Un mundo feliz, donde los individuos entran en estados sostenidos de euforia y placer mediante una droga llamada soma (Huxley, 1932).

Por tanto, el mind uploading no puede entenderse como un mero fenómeno tecnológico aislado, sino que se enmarca en un movimiento cultural y social que tiene una cosmovisión de lo humano centrada precisamente en la propia superación de lo humano en pos de lo post-humano o transhumano: el transhumanismo.

\subsection{Orígenes y defensores del mind uploading}

El mind uploading, pese a ser una realidad novedosa, descansa filosóficamente en temas que han sido tratados desde el propio origen de la filosofía, pues atañe directamente a la cuestión de la identidad personal. El mind uploading solo tiene sentido en su planteamiento si es capaz de mantener la identidad del sujeto en el propio proceso de preservar la mente de forma digital, lo cual es una concreción de la paradoja del barco de Teseo, al cual le fueron sustituyendo poco a poco las piezas hasta que no quedó ninguna original, suscitando la pregunta de hasta qué punto seguía siendo el mismo barco. De igual modo, al sustituir el sustrato biológico por otro 
¿Es realmente accesorio el cuerpo?

digital o robótico —o incluso otro biológico distinto al original— cabe preguntarse si la identidad se preserva o no.

No obstante, a nivel contemporáneo, el que se considera como trabajo germinal del mind uploading en su formulación actual es el realizado por Hans Moravec en su obra Mind Children: The Future of Robot and Human Intelligence (Moravec, 1988). En el capítulo llamado Transmigration, aborda la pregunta de si sería posible extraer la mente del cerebro. Para ello, propone un hipotético procedimiento donde un robot quirúrgico escanearía capas microscópicas del cerebro para construir un mapa en tres dimensiones del cerebro que sería implementado a un programa informático conectado al cerebro original. El proceso de transferencia sería muy gradual, transfiriéndose funciones paulatinamente, de forma que cuando el programa informático hubiera adquirido esas tareas, estas dejasen de funcionar en el cerebro original. Eventualmente, el cerebro dejaría de funcionar y el cuerpo moriría, pero la conciencia se habría transferido por completo al programa informático.

D. Charlmes (2010) sigue la estela de Moravec: describe un experimento mental donde se transfiere la mente de un sujeto ficticio llamado Dave a una emulación llamada Digi-Dave. Esta transferencia se puede realizar mediante dos procedimientos: El primero, mediante la transferencia paulatina de sus conexiones neuronales - muy similar al experimento de Moravec-; y el segundo, llamado copy-transfer, se basa en la tecnología de neuroimagen e impresión 3D: se crea una réplica del cerebro y en un segundo paso se realiza la transferencia.

A estos trabajos se suman muchos otros (se puede ver un listado más amplio en Cappuccio, 2017), como el del transhumanista Ray Kurzweil, que habla precisamente de la singularidad como el momento en el que seamos capaces de transcender nuestra dimensión biológica (Kurzweil, 2005) o el del autor K.B. Wiley, que profundiza más en los aspectos metafísicos de la cuestión (Wiley, 2014). Sin embargo, también existen detractores del mind uploading, ya sea por las dudas sobre su posibilidad o por su deseabilidad. 
Estos detractores se encuentran en su mayoría en las teorías del embodiment, que sostienen una visión de la mente no dualista (una panorámica de estos autores se encuentran recogidos en Gallagher, 2015).

\section{4 ¿En qué consiste el mind uploading?}

Si bien se ha tratado transversalmente el concepto de mind uploading, es pertinente para este trabajo clarificar qué se entiende exactamente por este término. La idea general está clara: subir la mente a un ordenador para obtener la inmortalidad. La definición exige por tanto conceptualizar la mente como algo que puede ser transferido, y que además puede serlo al margen de su contenedor original (el cuerpo biológico). Esto parece exigir una concepción dualista en filosofía de la mente, o al menos un cierto materialismo emanacionista, como señala Hopkins (2012), que sostendría que sería una transformación de materia y energía lo que produciría cambios en la cognición y la conciencia.

El receptor de la mente suele plantearse en general como un ordenador, pero en una definición más amplía habría que incluir otros cuerpos biológicos, pero también ciborgs y la propia red como un sustrato deslocalizado:

Mind-Uploading is the hope to create non-physical substrates, simulations, and duplicates of the human brain and its processes through brain imaging and subsequent algorithmic representations in computers and on the internet, as recommended by the second Global Future 2045 Congress of March 2013 in an open letter to United Nations Secretary-General Ban Ki-moon. The goal is to "upload" an individual mind into a non-biological substrate and thus free it from the limitations of the human body (Benedikter et al., 2017, p. 39).

No obstante, el núcleo del mind uploading no reside tanto en el receptor final sino en, como se ha comentado, en el propio concepto de transferir o trasladar una mente. Capuccio (2017) argumenta fuertemente a favor de este hecho clave del mind uploading, y sostiene que, en realidad, no tendría 
¿Es realmente accesorio el cuerpo?

que ver directamente con la paradoja del barco de Teseo, porque el problema no es si se puede reemplazar poco a poco un sustrato material, sino si, efectivamente, se pueden transferir estructuras formales de la mente.

\section{2. ¿Es posible el mind uploading?' Reflexión sobre la relación entre mente y cerebro}

\section{1 ¿Es replicable el cerebro?}

En este apartado se pretende abordar de forma breve algunas cuestiones sobre la posibilidad real del mind uploading. La primera cuestión que surge, más allá de la transferencia de la mente al replicar un cerebro, es la propia replicación del cerebro, ya sea una copia biológica, una réplica digital o una simulación cibernética. La primera dificultad es el número de neuronas, que se sitúa en torno a los 100 billones (Kandel, Schwartz, \& Jessell, 2000), un número nada despreciable a pesar de la capacidad de computación creciente de nuestros ordenadores. Sin embargo, la replicación del cerebro no se limita a las neuronas, sino que es crucial simular las conexiones entre ellas, cuya velocidad supera los $400 \mathrm{~km} / \mathrm{h}$. No obstante, a pesar de la complejidad, cabría pensar que podría ser posible, en vista de los avances realizados con el superordenador Blue Gene (Markram, 2006).

Sin embargo, ¿'es suficiente replicar neuronas y conexiones para generar un cerebro funcional, e incluso la mente vinculada a ese cerebro? La verdad es que no se sabe con certeza cómo funciona el cerebro en su conjunto, y suponer que replicando el sustrato se va a replicar automáticamente el funcionamiento es una asunción que necesita justificación. Lo que nuestro conocimiento del cerebro sí nos permite cuestionar es el planteamiento de los experimentos ficticios de Moravec (REF) o Chalmers (REF) que involucran una transferencia paulatina de funciones del cerebro, como si existiese una compartimentación total de funciones cerebral. De hecho, la neurociencia apunta cada vez más que la asignación de funciones a zonas 
concretas del cerebro —entendidas aisladamente- es cada vez menos sostenible, pues una función no depende de una zona, sino de la interacción de varias zonas que actúan conjuntamente. El solapamiento existente entre áreas y funciones hace imposible sostener ya, aunque solo sea conceptualmente, la posibilidad de transferir funciones aisladas de un cerebro a su réplica (lo cual está en la base de muchos modelos de transferencia).

\section{2 ¿Qué es la mente?}

La segunda cuestión que es pertinente abordar al plantear la posibilidad de realizar el mind uploaging es la naturaleza de la mente. Paradójicamente, en un planteamiento donde el tema central es el traslado de la mente, hay un vacío en la reflexión sobre qué es la mente y, por ende, si puede ser trasladada, replicada, etc. De hecho, se funciona con una concepción difusa asumida culturalmente de la mente que responde a una visión dualista del ser humano, donde la mente es independiente del propio cuerpo. En esta visión, el término mente viene a sustituir en el inconsciente cultural a la noción de alma, entendida como aquello inmaterial que no está conectado directamente con lo biológico: el pensamiento, las decisiones, los recuerdos, etc.

Sin embargo, ¿cabe separar realmente estos procesos de su sustrato? Sin llegar a afirmar que estos procesos se identifiquen con su sustrato, ¿̇es posible desvincular totalmente los procesos del sustrato? Pensamos en el caso de la memoria, que es un elemento relevante en la identidad: ¿no tiene nada que ver con el sustrato neurológico? Es cierto que la analogía informática incita a concebir la información como no dependiente del soporte donde se almacena, pero ¿es lo mismo almacenar información digital que almacenar toda una vida de vivencias y recuerdos? Piénsese en la memoria procedimental: esta memoria no se centra en el qué sino en el cómo, y se concreta en los hábitos (Bernacer \& Murillo, 2014). Es diferente tener el recuerdo de haber aprendido a andar en bici a tener el hábito de andar en bicicleta. Lo mismo ocurre con tocar el piano o utilizar un tenedor. ¿Cómo 
¿Es realmente accesorio el cuerpo?

se transfiere este tipo de memoria a un ordenador? ¿Cabe decir que se ha transferido el conocimiento de andar en bicicleta si no hay un entramado de nervios, músculos, huesos, etc., que estén conectados a este sistema?

Por otro lado, si bien la inteligencia encaja bien en este esquema de corte dualista por su carácter formal cocurre lo mismo con la afectividad? ¿Cabe transferir el contenido emocional y las singularidades afectivas de la personalidad de cada uno a una réplica digital del cerebro? Incluso si se piensa en transferir el cerebro a otro cuerpo orgánico ¿̇se puede sentir de la misma manera en un cuerpo ajeno? Muchas preguntas y pocas respuestas, pero es pertinente al menos hacer ver que la cuestión de la mente y su naturaleza no es tan trivial como a veces se asume.

\subsection{Dualismo frente a las teorías del embodiment en la relación mente-cerebro y sus consecuencias para el mind uploading}

Por tanto, se adivina que lo que está de fondo en el debate del mind uploading es una comprensión dualista de la relación mente-cerebro frente a una concepción no dualista, que sostiene que el vínculo entre el cuerpo y la mente es más relevante de lo que el mind uploading sostiene (las llamadas teorías del embodiment a nivel contemporáneo o la antropología aristotélica que responde al dualismo platónico de su época).

Es pertinente señalar como hay una cierta tendencia a una comprensión dualista del ser humano, que, a mi juicio, reposa en la reificación de la mente o el alma, por una razón de economía cognitiva: es más sencillo conceptualizar la mente y el cuerpo como "cosas" que interactúan entre sí más que como principios reales ${ }^{1}$. En neurociencia y filosofía de la mente es el dualismo cartesiano el que más presente está, debido a esta tendencia dualista enraizada culturalmente pero también porque es un esquema sencillo que permite hacer neurociencia de forma compartimentada: separando el

1 Esta inclinación natural al dualismo ha sido recogida por Paul Boom en su libro Descartes Baby: How the Science of Child Development Explains What Makes Us Human (Bloom, 2004). 
sustrato biológico de los procesos mentales. De esta forma, se explica mejor cómo el mind uploading suena más razonable de lo esperado, ya que encaja con el marco conceptual implícito en nuestra cultura.

Hopkins (2012) hace una reflexión interesante a este respecto: hasta los autores que se definen como materialistas se ven obligados tácitamente a actuar como dualistas para preservar la identidad de la mente: si no hay una mente con una entidad propia al margen del cuerpo, es difícil entender cómo cambiando las condiciones materiales hay una continuidad de la identidad.

\section{La cuestión de la identidad: ¿sigo estando ahí?}

Como se acaba de comentar, la cuestión de la identidad es un punto neurálgico del mind uploading: ¿qué tipo de inmortalidad cabe esperar si mi yo desaparece en el proceso? Por tanto, la pregunta clave para el mind uploading es "¿isigo estando allí?". Es cierto que hay ciertas propuestas más blandas que admiten explícitamente que no aspiran a la inmortalidad personal, sino a hacer una copia virtual que, mediante un avatar, se comporte de forma similar al original; en concreto que pueda mantener conversaciones que superen el Test de Turing. Es el caso del robot BINA48 (Breakthrough Intelligence via Neural Architecture 48), que ha sido descrito como un "robot sintiente", un "compañero cibernético" o un "robot social" (Harmon, 2010). No obstante, la mayor parte del movimiento a favor del mind uploading sostiene la posibilidad real de mantener la identidad personal en el proceso de transferencia. Al mismo tiempo, este elemento es la principal razón que, según un estudio sociológico sobre la cuestión (Laakasuo et al., 2018) las personas esgrimen para rechazar el mind uploading: genera rechazo el propio acto de transferir la conciencia fuera de uno mismo.

Una cuestión relevante respecto a la identidad es ¿̇cuándo se realiza esta transferencia? Si hacemos una copia física de una mente (incluso con un cuerpo biológico idéntico al original) ¿̇uándo se produce la transferencia? 
¿Es realmente accesorio el cuerpo?

¿al morir el sujeto automáticamente el otro "despierta"? ¿O, por el contrario, cabe una transferencia "activa" de la mente de un cuerpo a otro en el momento deseado? Aquí surgen contradicciones porque si para duplicar una mente solo hace falta generar una copia o réplica resulta difícil establecer el momento de activación. Y, si la transferencia se puede activar el proceso en el momento deseado, ¿cómo se podría activar la transferencia de algo que de por sí es inmaterial? ¿Realmente cabe un "mover" una mente, que por definición no es material y, por ende, no tiene una ubicación especial? Si nos ceñimos al materialismo, la mente es un epifenómeno, y al copiar las condiciones materiales se generaría una mente, pero surgiría la paradoja de tener varias copias de una persona que en teoría siguen siendo ella misma. Pero, desde el dualismo, surge la complicación antes mencionada: se acaba sosteniendo la transferencia como una traslación de algo que por definición no es trasladable en cuanto no posee una ubicación.

Capuccio (2017) enuncia tres asunciones que el mind uploading debe sostener para asegurar que la identidad personal se transfiere en el proceso. En primer lugar, el neurocentrismo (que puede incluir el neuroreduccionismo), que implica que una descripción exhaustiva de la actividad cerebral hace posible un análisis total de la mente. Esto es necesario porque el mind uploading se base en la replicación del cerebro y no de todo el cuerpo: si la identidad y la mente dependen de algo más allá del propio cerebro, no cabría mantener la identidad replicando solo el cerebro. Esta asunción es cuestionada por las teorías del embodiment, que sostienen que toda la constitución biológica es relevante para la identidad. Un ejemplo de ello sería la percepción, donde la configuración estructural de los propios órganos sensoriales afectarían a la propia percepción (Güell \& Bernácer, 2015).

La segunda asunción es el formalismo (que puede implicar funcionalismo y una teoría computacional de la mente), por el cual la actividad neuronal es reductible a estructuras formales y puede ser reproducida por otros sustratos materiales. Esto es lo que ocurría en el caso que señalábamos de la memoria: hay una concepción formal del contenido y de los procesos, 
de tal forma que podrían darse en sustratos totalmente diferentes a los datos (igual que un software puede ejecutarse en diferentes configuraciones de hardware). El mind uploading lo requiere porque en otro caso no cabría trasladar la identidad y sus procesos (entendidos en clave formal) a un sustrato diferente. La convicción de fondo es que "lo que funciona como un cerebro producirá el mismo resultado que un cerebro" (Benedikter et al., 2017, p. 60).

La tercera asunción el ultrafuncionalismo, por el cual un conjunto de estructuras formales y procesos que constituyen la actividad cerebral de una persona pueden ser reubicadas en otro sustrato manteniendo la unidad. Sin este requisito no se puede asegurar la continuidad de la identidad. Se trata de una especie de idealismo funcionalista que es reinterpretado materialistamente para servir de marco filosófico para el transhumanismo y el mind uploading.

Esto lleva a la existencia de dos requisitos necesarios para el mind uploading pero que resulta contradictorios (Cappuccio, 2017): el requisito de trascendencia y el requisito de individuación. El requisito de trascendencia consiste en que la concreción material de una mente no contribuye a su estructura formal; si no se da, no se puede reubicar la mente, porque habría un vínculo no accesorio entre mente y sustrato material. Por otra parte, el requisito de individuación exige que la mente y sus componentes sean identificables numéricamente, ya que, si no, no sería posible afirmar que una estructura formal —una identidad - se haya transferido. Estos requisitos contradictorios llevan a la reificación de las mentes, convirtiendo las mentes en una suerte de elementos "pseudo-físicos", pues no son físicos en cuanto son una mente, pero se comportan como físicos en cuanto a la propiedad de ser transferidas. 
¿Es realmente accesorio el cuerpo?

\section{4. ¿Es deseable el mind uploading?' Efectos colaterales que deben ser tenidos en cuenta}

\subsection{La percepción de la sociedad}

Junto a la cuestión de la posibilidad —que no ha sido cerrada en el apartado anterior, pero si al menos problematizada- está la cuestión de la deseabilidad. Presuponiendo que el mind uploading sea efectivamente realizable y la identidad personal se preserve ces deseable para el ser humano la transformación del mundo que se produciría al introducir este elemento? Se está planteando una transformación radical que afectará a nivel social, político, económico, cultural, psicológico, etc.

La cuestión del mind uploading se presenta ahora como un producto de ciencia ficción en clave utópica, pero no se analizan bien todas las transformaciones que se producirían si se llegase a implementar a gran escala. De hecho, esta transformación hacia lo transhumano es precisamente la intención del transhumanismo, con lo que la deseabilidad de la transformación no se plantea en cuanto es precisamente el presupuesto del propio transhumanismo: que la transformación de lo humano hacia lo post-humano es deseable y generará bienestar. Sin embargo, el estudio sociológico de Laakasuo (2018) muestra que no hay consenso social en la aceptación del mind uploading y sus consecuencias. En concreto, hay una ligera mayor aceptación en la gente joven pero no encontraron efectos al modificar las condiciones prácticas del mind uploading (receptor de la mente, uso de agujas, etc.), sino que el elemento crítico para la aceptación o no era el propio hecho de transferir la propia conciencia fuera de sí.

En este sentido, se van a analizar algunos efectos colaterales del mind uploading que van más allá de lo tecnológico que deben ser tenidos en cuenta en una valoración global del mismo. 


\subsection{La capacidad de comunicación}

Una cuestión de gran interés es la relativa a cómo sería la comunicación tras el hipotético mind uploading. Se pueden distinguir tres situaciones diferenciadas respecto a este tema: que la mente sea transferida a un entorno virtual, a un cuerpo robótico o a otro cuerpo humano.

El primer caso es el más extremo ya que generaría la transformación más grande, pues se anularía la mediación física del cuerpo en la comunicación, siendo este sustituido por avatares virtuales no limitados las condiciones espaciales: un avatar digital no está propiamente ubicado físicamente en un sitio, pues a pesar de tener un soporte hardware, su ubicación es difusa, pues puede transferirse de soporte en soporte. En este aspecto el concepto de la nube como entorno on-line tiene mucha relevancia: nuestra mente podría estar almacenada en la nube, de forma que podría ubicarse en cualquier lugar donde hubiera soporte para ello. Hay voces que sostienen que este podría ser un paso hacia delante, en cuanto se podría transferir información directamente de mente a mente, sin la limitación de percibir la información indirectamente mediante palabras o gestos. Esto podría aplicarse también en el caso de cuerpos robóticos o cuerpos humanos que estuviesen mejorados mediante una conexión a la nube que permitiera esta misma comunicación.

La pregunta es, entonces, si el cuerpo es posibilidad o límite de la comunicación. Para que sea límite, habría que aceptar que la comunicación corporal es imperfecta y, sobre todo, que lo realmente importante cabe ser transferido como información. Por ejemplo, si es conceptualizable la comunicación del amor de una persona u otra codificada como información que pueda ser transmitida directamente entre mentes. En mi opinión, lo radical del ser humano rebasa el ámbito de la objetividad y, por tanto, de lo que puede ser encapsulado a modo de información, por lo que se comunica como apertura de una intimidad encarnada, en la que el cuerpo no es límite sino vehículo posibilitador de la apertura de un ser personal a otro. 
¿Es realmente accesorio el cuerpo?

\subsection{El estatuto de la mente subida}

Otra cuestión que habría que plantearse qué estatuto tendría la mente subida. La opción más sencilla es que sigamos siendo organismos "cerrados": a cada mente le correspondería un cuerpo físico; pero ¿qué ocurre en el caso de la opción de los avatares digitales mencionada en el apartado anterior? En ese caso habría que hacer una reflexión a muchos niveles sobre cómo se consideraría a dicha mente cuya localización es difusa ċómo se podría localizar a dicha mente? ¿cómo podría ser recluida una mente que cometería algún crimen al modo en que ahora funcionan las prisiones? ¿sería considerado un asesinato la destrucción del contenido digital que corresponde a esa mente? Se refleja aquí con claridad que el mind uploading exige no solo una solución tecnológica, sino también una elaboración social, política y legislativa.

\subsection{La seguridad tras el uploading}

De igual modo ¿estaríamos seguros con nuestra mente subida a un entorno digital? Hipotéticamente, a una mente en un entorno digital se le podría simular en contra de su voluntad sensaciones como el dolor. En la película Matrix (Lana Wachowski, 1999) personas con su mente conectada a una simulación digital pueden llegar a sentir dolor e incluso llegar a morir en el caso de que se produzca la muerte en el entorno digital. En este sentido, la existencia de hackers que puedan manejar en contra de su voluntad a las mentes que hayan sido subidas es una amenaza muy grande. Y, a gran escala, la posibilidad de manipulación y de control social sería una amenaza aún mayor, haciendo palidecer las reflexiones sobre el Gran Hermano del libro 1984 (Orwell, 2010). 


\subsection{Acceso al mind uploading}

Otra pregunta que surge en el caso de que el mind uploading fuese posible e incluso deseable es: ¿cómo se gestionaría el acceso de las personas al mind uploading? No es difícil imaginar que siendo un procedimiento tan novedoso y tecnológicamente complejo suponga un gran coste económico ¿sería entonces el acceso a la inmortalidad una cuestión de estatus económico? Las referencias cinematográficas distópicas son muy iluminadoras en este sentido: La película In time (Niccol, 2011) presenta un futuro donde cada persona tiene un contador del tiempo que le queda para morir: si el contador llega a cero, la persona muere. En ese mundo cabe la posibilidad de comprar tiempo — de hecho, los sueldos y las transacciones económicas se hacen mediante segundos y no mediante monedas-, siendo la posibilidad de eludir la muerte un bien de consumo solo al alcance de unos pocos.

En la misma línea del mind uploading está la cuestión más amplia del enhacement: la posibilidad de mejorar tecnológicamente los cuerpos humanos. Desde esta perspectiva podría ocurrir la generación de clases sociales en función del grado de mejora de sus cuerpos, siendo los más mejorados aquellos con mayor poder adquisitivo. Llevando la cuestión hasta el extremo, podría aparecer una nueva clase de racismo que más bien sería un especismo muy elaborado, donde hubiera discriminación y rechazo a las personas que fueran eminentemente humanas y no post-humanas.

\section{6 ¿Es malo morirse? El horizonte existencial}

No obstante, la gran pregunta que realmente pone en jaque la deseabilidad del mind uploading es precisamente si la eliminación de la muerte del horizonte humano conlleva una mejora global de la vida humana.

El filósofo alemán Martin Heidegger definía al ser humano como un ser para la muerte (Heidegger, 2008), en cuanto que el existente - o daseines un ser en cuya condición radical está inscrita la posibilidad de dejar de existir. En este sentido, cabría preguntarse si este horizonte existencial de 
¿Es realmente accesorio el cuerpo?

finitud es algo accesorio que puede ser desgajado del ser humano sin desvirtuarlo.

Steve Jobs, fundador y CEO de Apple, poco sospechoso de estar en contra del desarrollo tecnológico, pronunciaba esta reflexión sobre el tema de la muerte en el discurso de graduación de la Universidad de Stanford de 2005:

Recordar que voy a morir pronto es la herramienta más importante que haya encontrado para ayudarme a tomar las grandes decisiones de mi vida. Porque prácticamente todo, las expectativas de los demás, el orgullo, el miedo al ridículo o al fracaso se desvanece frente a la muerte, dejando sólo lo que es verdaderamente importante. Recordar que vas a morir es la mejor forma que conozco de evitar la trampa de pensar que tienes algo que perder. Ya estás desnudo. No hay razón para no seguir tu corazón.

Hace casi un año me diagnosticaron cáncer. Me hicieron un chequeo a las 7:30 de la mañana, y mostraba claramente un tumor en el páncreas. Ni siquiera sabía qué era el páncreas. Los médicos me dijeron que era prácticamente seguro un tipo de cáncer incurable y que mi esperanza de vida sería de tres a seis meses. Mi médico me aconsejó que me fuese a casa y dejara zanjados mis asuntos, forma médica de decir: prepárate a morir.

Significa intentar decirles a tus hijos en unos pocos meses lo que ibas a decirles en diez años. Significa asegurarte de que todo queda atado y bien atado, para que sea tan fácil como sea posible para tu familia. Significa decir adiós. Viví todo un día con ese diagnóstico.

Luego, a última hora de la tarde, me hicieron una biopsia, metiéndome un endoscopio por la garganta, a través del estómago y el duodeno, pincharon el páncreas con una aguja para obtener algunas células del tumor. Yo estaba sedado, pero mi esposa, que estaba allí, me dijo que cuando vio las células al microscopio el médico comenzó a llorar porque resultó ser una forma muy rara de cáncer pancreático que se puede curar con cirugía.

Me operaron, y ahora estoy bien. Esto es lo más cerca que he estado de la muerte, y espero que sea lo más cerca que esté de ella durante algunas décadas más. Habiendo vivido esto, ahora os puedo decir esto con más certeza que cuando la muerte era un concepto útil, pero puramente intelectual: 


\section{Mikel Ostiz Blanco}

Nadie quiere morir. Ni siquiera la gente que quiere ir al cielo quiere morir para llegar allí. Y sin embargo la muerte es el destino que todos compartimos. Nadie ha escapado de ella. Y así tiene que ser, porque la Muerte es posiblemente el mejor invento de la Vida. Es el agente de cambio de la Vida. Retira lo viejo para hacer sitio a lo nuevo (Steve Jobs, 2005).

La muerte no es en sí misma un bien, pero el horizonte existencial de finitud del ser humano parece algo que no es tan accesorio como podría serlo por ejemplo eliminar la alergia al polen de la faz de la Tierra. Esta es, en el fondo, la gran pregunta que habría que responder para dar cuenta de la deseabilidad del mind uploading ces deseable eliminar el horizonte de finitud humano?

\section{Consideraciones finales}

\subsection{Utopía más que evidencia científica}

A modo de cierre, se recapitulan aquí las principales conclusiones de esta reflexión, que es de carácter abierto, pues pretende problematizar y abrir interrogantes más que dar respuestas cerradas.

La primera conclusión es que el mind uploading no es una propuesta científica, sino que su origen es el de una concepción cultural respecto al ser humano y su relación con la tecnología. A pesar de ser un movimiento cuyas esperanzas van de la mano de la ciencia y la tecnología, el transhumanismo en sí mismo no es un movimiento científico sino una concepción antropológica de lo que el ser humano es y sobre todo de lo que puede llegar a ser. En este sentido, su propuesta tiene un cierto carácter utópico en cuanto horizonte al que tender, si bien se presenta a sí mismo como una propuesta científica.

El presupuesto base del transhumanismo de que el avance tecnológico de mejora del ser humano va a traer nuevas cotas de bienestar no es una hipótesis científica sino más bien una interpretación antropológica, social y 
¿Es realmente accesorio el cuerpo?

cultural. De hecho, existen importantes voces dentro del mundo de la industria tecnológica que tienen ciertas dudas a este respecto. Steve Wozniak's, cofundador de Apple, ofrece una visión no tan positiva del avance tecnológico, llegando a sostener que los ordenadores van a sobrepasar a los seres humanos, planteándose un futuro un tanto inquietante ${ }^{2}$. Por otra parte, Elon Musk, lider de Tesla Motors and Space X, a pesar de ser uno de los grandes propulsores del avance tecnológico, se ha erigido como una voz preocupada por el avance de la inteligencia artificial, llegando a donar 10 millones de dólares al Future of Life Institute con el objetivo de lograr que la inteligencia artificial siga siendo beneficiosa para el ser humano.

\subsection{Dificultades en el marco filosófico}

La segunda gran conclusión es que el concepto del mind uploading es en sí mismo problemático a nivel filosófico. Como se ha comentado en la segunda sección de este artículo, falta una justificación rigurosa sobre qué es una mente y si es posible transferirla de un sustrato a otro. Hay tres grandes posturas de filosofía de la mente sobre este tema: las teorías del embodiment, el dualismo y el materialismo. El primero rechaza la posibilidad del mind uploading porque se basa en una unión no accidental entre cuerpo y mente, no siendo estos dos elementos separables. En el caso del dualismo, la mente aparece como algo independiente, pero en ese caso surge el problema de cómo algo inmaterial —en cuanto la mente se define por su inmaterialidad frente a lo material o físico- puede ser trasladado en cuanto por definición no tiene localización. Y, por último, el materialismo concibe la mente como una mera emanación de la materia, con lo que resulta difícil justificar cómo sustituyendo el sustrato material se puede dar lugar a la misma mente original.

2 "Computers are going to take over from humans [...] the future is [therefore] scary and very bad for people" (Smith, 2015). 
Mikel Ostiz Blanco

\subsection{La razón antropológica: la dificultad para aceptar la finitud}

Y, por último, la conclusión final es que el tema del mind uploading y del transhumanismo en general tiene que ver en su raíz con cuestiones antropológicas y no tanto tecnológicas, pues hay una clara determinación de ser capaces de superar la limitación y la finitud del ser humano a través del surgimiento del post-humano. De hecho, el transhumanismo conlleva en cierto sentido una ruptura con el humanismo y el posthumanismo ya que la cultura occidental nace y crece en el humanismo. En los años 70 y 80 surge la corriente del posthumanismo que, aunque pretende superar el humanismo, tiene una cierta continuidad en cuanto comparte la visión del ser humano como un ser finito y limitado. El transhumanismo se opone a ambos en cuanto ve en la tecnología el medio para superar las limitaciones del ser humano (Benedikter et al., 2017).

En esta línea de reflexión antropológica, es interesante la interpretación de Capuccio (2017), que relee la cuestión del mind uploading precisamente como un dilema entre la prioridad de la esencia o la existencia. El mind uploading daría prioridad a la esencia en cuanto al qué, en cuanto a la mente en su dimensión entitativa en cuanto puede ser entendida como un objeto susceptible de ser trasladado en abstracto, sin vinculación constitutiva con sus condiciones reales. Por el contrario, las teorías del embodiment, darían más prioridad a la existencia en cuanto a la condición real y efectiva de una esencia. Y, en la base de todo esto, está un debate en torno a la naturaleza de la libertad, ya que para los defensores del mind uploading y del transhumanismo en general, cabría decir que el cuerpo en cuanto condición real y concreta constituye una limitación que debe ser superada ${ }^{3}$. Frente a ello, la existencia en cuanto condición concreta sería no limitación sino posibilidad

3 Existiría de hecho un eco de la antropología platónica del cuerpo como cárcel del alma, donde la liberación consistiría en un ejercicio purgatorio desde lo material a lo más ideal o abstracto, que es precisamente lo que busca el mind uploading, la liberación de las condiciones materiales en pos de un nuevo estadio caracterizado por la formalidad y la independencia del sustrato. Para el mind uploading, como para Platón, sería casi una cuestión de azar que nuestras mentes estén encerradas en este cuerpo concreto. 
¿Es realmente accesorio el cuerpo?

real de libertad, la cual no se puede ejercer en el vacío sino precisamente solo en el seno de unas circunstancias concretas, de una realidad que no solo es abstracta sino efectiva.

Somos seres finitos cuya libertad se despliega en el marco de unas condiciones espaciales y sobre todo temporales, y la gran pregunta es si la eliminación de esta condición existencial es realmente un camino de liberación, si el paso del ser humano al ser post-humano es realmente un avance posible y, sobre todo, deseable. La respuesta no es sencilla. Lo que está claro es que no se trata de una cuestión ni sencilla ni resuelta, y que está en juego la comprensión de que es precisamente una vida humana y el camino para lograr la mejor vida posible (ya sea humana, post-humana o transhumana).

\section{Bibliografia}

Benedikter, R., Siepmann, K., \& Reymann, A. (2017). "Head-transplanting” and "Minduploading": Philosophical implications and potential social consequences of two medicoscientific utopias. Review of Contemporary Philosophy, 16, 38-82. http://doi.org/http://dx.doi.org/10.22381/RCP1620172

Bernacer, J., \& Murillo, J. I. (2014). The Aristotelian conception of habit and its contribution to human neuroscience. Frontiers in Human Neuroscience, 8. http://doi.org/10.3389/fnhum.2014.00883

Bloom, P. (2004). Descartes' baby: How the Science of Child Development Explains What Makes Us Human. Descartes Baby. http://doi.org/10.1111/j.1468-2346.2012.01079.x

Cappuccio, M. L. (2017). Mind-upload. The ultimate challenge to the embodied mind theory. Phenomenology and the Cognitive Sciences, 16(3), 425-448. http://doi.org/10.1007/s11097-016-9464-0

Chalmers, D. J. (2010). The singularity: A philosophical analysis. Journal of Consciousness Studies, 1-56. http://doi.org/10.1016/0022-0396(79)90001-9

Gallagher, S. (2015). Invasion of the body snatchers: how embodied cognition is being de-radicalized.

Güell, F., \& Bernácer, J. (2015). Anatomical constitution of sense organs as a marker of mental disorders. Frontiers in Behavioral Neuroscience, 9, 59. http://doi.org/10.3389/fnbeh.2015.00059 


\section{Mikel Ostiz Blanco}

Harmon, A. (2010). Making Friends with a Robot Named BINA48. The New York Times. Retrieved from http://www.nytimes.com/2010/07/05/science/05robotside. html?_r $=0$

Heidegger, M. (2008). Ontología. Hermenéutica de la facticidad. Madrid: Alianza.

Hopkins, P. D. (2012). Why uploading will not work, or, the ghost haunting transhumanism. International Journal of Machine Consciousness, 04(01), 229-243. http://doi.org/10.1142/S1793843012400136

Huxley, A. (1932). Un mundo feliz. DEBOLSILLO.

Kandel, E. R., Schwartz, J. H., \& Jessell, T. M. (2000). Principles of Neural Science. Neurology (Vol. 4). http://doi.org/10.1036/0838577016

Krishnan, R. (2012). From Jugaad to Systematic Innovation: Disruptive \& Radical Innovation: How are they different? Retrieved from http://jugaadtoinnovation. blogspot.com.es/2012/08/disruptive-radical-innovation-how-are.html

Kurzweil, R. (2005). The singularity is near. viking (Vol. 45). http://doi.org/10.1109/MSPEC.2008.4635038

Laakasuo, M., Drosinou, M., Koverola, M., Kunnari, A., Halonen, J., Lehtonen, N., \& Palomäki, J. (2018). What makes people approve or condemn mind upload technology? Untangling the effects of sexual disgust, purity and science fiction familiarity. Palgrave Communications, 4(1), 84. http://doi.org/10.1057/s41599-018-0124-6

Lana Wachowski, L. W. (1999). Matrix.

Markram, H. (2006). The Blue Brain Project. Nature Reviews Neuroscience. http://doi.org/10.1038/nrn1848

Moravec, H. (1988). Mind Children: The Future of Robot and Human Intelligence. Mind Children The Future of Robot and Human Intelligence (Vol. February 1). http://doi.org/cblibrary-fut

Niccol, A. (2011). In time.

Orwell, G. (2010). 1984. Destino.

Smith, P. (2015). Apple Co-founder Steve Wozniak on the Apple Watch, Electric Cars and the Surpassing of Humanity. AFR Weekend.

Stanford, U. (n.d.). Program on Liberation Technology.

Steve Jobs. (2005). Stanford University Commencement Address. Stanford Reports.

The immortality bus. (n.d.). Retrieved September 20, 2018, from http://www.immortalitybus.com

Wiley, K. (2014). A taxonomy and metaphysics of mind-uploading. Humanity+ Press and Alautun Press.

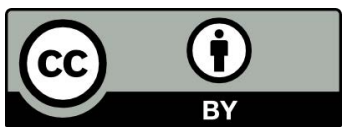

Mikel Ostiz Blanco mostiz.1@alumni.unav.es 